\title{
PERILAKU HARIAN KUSKUS BERUANG (Ailurops Ursinus) DI KAWASAN KONSERVASI CAGAR ALAM TANGALE
}

\author{
(Bear Cuscus (Ailurops Ursinus) Behavior In Tangale Natural Reserve \\ Conservation Area)
}

\author{
Moen Sara $^{1)}$, Bachtiar $^{2)}$, Dian Puspaningrum ${ }^{3)}$ \\ Fakultas Kehutanan Universitas Gorontalo \\ ${ }^{1}$ E-mail: moensara17@gmail.com ${ }^{1}$,tiarfpug@gmail.com ${ }^{2}$,dian_puspaningrum@unigo.ac.id ${ }^{3}$
}

\begin{abstract}
Bear cuscus (Ailurops ursinus) is an endemic fauna that has been protected since 1990. The conservation of the bear cuscus as a protected wild animal is determined, one of which is its life activity in nature. This study aims to determine the daily activities and behavior of bear couscous in the Tangale Nature Reserve. The method used in this study is the path method (transect) by direct observation in the field. Behavior variablr which observe in this research are rest, eat, move places, stay still, and care for the body/grooming. The analysis data used quantitative analysis and descriptive. The observation started at 05:00 in the morning until 17:00 in the aftternoon during 49 days. The findings revealed that daily activities of bear cuscus are rest 370 minutes (52\%), eat 160 minutes (22\%), move places 60 minutes (8\%), stay still 95 minutes (13\%), care for the body/grooming 35 minutes (5\%) total of daily activities time. The cuscus bear spent the most time on rest and grooming and id the smallest quantity time which doing by bear cuscus.
\end{abstract}

Keywords: Nature Reserve, Endemic Fauna, Bear Cuscus

\begin{abstract}
Abstrak
Kuskus Beruang (Ailurops Ursinus) adalah fauna endemik yang dilindungi sejak tahun 1990. Kelestarian kKuskus Beruang sebagai hewan liar yang dilindungi ditentukan salah satunya adalah aktifitas hidupnya di alam. Penelitian ini bertujuan untuk mengetahui perilaku harian Kuskus Beruang di Cagar Alam Tangale. Metode yang digunakan dalam penelitian ini adalah metode jalur (transek) dengan cara observasi langsung di lapangan. Varibel perilaku yang diamati dalam penelitian adalah istirahat, makan, berpindah tempat, diam, dan merawat tubuh/grooming. Analisis data yang dilakukan adalah analisis kuantitatif dan deskriptif. Pengamatan dilakukan mulai pukul 05:00 pagi sampai 17:00 sore, selama 49 hari pengamatan. Hasil penelitian menunjukan bahwa aktifitas harian Kuskus Beruang antara lain istirahat selama 370 menit (52\%), makan 160 menit (22\%), berpindah tempat 60 menit (8\%), diam 95 menit (13\%), dan merawat tubuh/grooming 35 menit (5\%) total waktu aktifitas harian. Kuskus Beruang menghabiskan waktu terbanyak pada aktifitas istirahat dan aktifitas grooming adalah aktifitas dengan kuantitas waktu terkecil yang dilakukan Kuskus Beruang.
\end{abstract}

Kata kunci : Cagar Alam, Fauna endemik, Kuskus Beruang 


\section{PENDAHULUAN}

Kuskus Beruang (Ailurops ursinus) merupakan jenis marsupialia yang tergolong dalam famili phalagaridae dan merupakan famili dengan penyebaran yang cukup luas diantara jenis marsupialia lainnya. Kuskus Beruang di Indonesia sudah dilindungi sejak tahun 1990 melalaui Peraturan Perburuan Binatang Liar (PPBL) No. 226/1931 dan UU Nomor 7 Tahun 1999 tentang Pengawetan Jenis Tumbuhan dan Satwa. (Saragih et.al, 2010). Ancaman utama bagi Kuskus Beruang adalah hilangnya sebagian habitat yang disebabkan oleh penebangan hutan untuk lahan pertanian skala kecil maupun penebangan skala besar (Darenoh et.al, 2019).

Daerah sebaran Kuskus Beruang hanya terdapat di Sulawesi dan pulau kecil lainnya, salah satunya pada Kawasan Konservasi Cagar Alam Tangale. Namun sering berjalannya waktu, populasi Kuskus Beruang di Cagar Alam Tangale sudah mengalami penurunan akibat aktifitas manusia antara lain perambahan dan kebakaran hutan yang terjadi beberapa tahun terakhir. Menurut pengelola kawasan Cagar Alam Tangale populasi Kuskus Beruang sendiri mulai mengalami penurunan sejak tahun 2017, akibat adanya aktivitas manusia seperti kegiatan perambahan dan kebakaran hutan.

Berkaitan dengan adanya penurunan populasi Kuskus Beruang, maka perlu adanya upaya konservasi salah satu aspek pendukung yaitu penelitian yang mengkaji tentang perilaku harian Kuskus Beruang yang ada di kawasan Cagar Alam Tangale.

HASIL DAN PEMBAHASAN

\section{Aktifitas Kuskus Beruang selama istirahat.}

Belum adanya penelitian mengenai Kuskus Beruang (Ailurops ursinus) di Provinsi Gorontalo Khususnya di Cagar Alam Tangale Menjadi salah satu alasan penelitian ini dilaksanakan.

\section{METODOLOGI PENELITIAN}

Penelitian ini dilaksanakan pada bulan April sampai dengan bulan Mei 2019, di Kawasan Konservasi Cagar Alam Tangale, Kecamatan Tibawa, Kabupaten Gorontalo. Alat dan bahan yang diguankan dalam penelitian ini antara lain: aplikasi GPS essentials, stopwatch, kamera, alat tulis menulis, dan peta kawasan.

Sumber data yang dikumpulkan dalam penelitian ini meliputi data primer yang meliputi data hasil pengamatan perilaku harian Kuskus Beruang dan data Sekunder yang meliputi data penunjang maupun referensi yang diperoleh dari pihak/instansi terkait. Teknik pengumpulan data yang dilakukan dalam penelitian ini adalah membuat jalur transek, mengambil bukti dokumentasi pengambian sampel di lapangan, dan wawancara dengan pihak terkait.. Analisis data yang dilakukan adalah analisis kuantitatif dan deskriptif. Analisis kuantitatif dilakukan dengan menggunakan rumus sebagai berikut:

Presentase Tingkah Laku $(\%)=\frac{\mathbf{A}}{\mathbf{B}} \times 100$

Keterangan:

$\mathrm{A}=$ Waktu yang digunakan untuk suatu tingkah laku dalam satu hari pengamatan

$\mathrm{B}=$ Total Waktu Pengamatan dalam satu hari (720 menit)

Perilaku Kuskus Beruang sedang istirahat terlihat pada saat Kuskus Beruang mulai berjalan menuju bagian ujung pohon bersiap-siap untuk tidur. 
Tabel 1. Waktu aktifitas Kuskus Beruang selama istirahat

\begin{tabular}{lll}
\hline Waktu & Lama aktifitas & \\
\cline { 2 - 3 } Pengamatan & Jam & Menit \\
\hline Pagi & $05: 00-07: 00$ & 120 \\
Siang & $10: 00-11: 30$ & 90 \\
& $12: 20-15: 00$ & 160 \\
Sore & - & - \\
\hline
\end{tabular}

Sumber: Data primer setelah diolah, 2019

Tabel 1 menunjukkan bahwa Kuskus Beruang memiliki waktu aktif mulai pagi sampai dengan siang hari. Selain menggunakan waktunya untuk mecari makan, waktu Kuskus berunag juga digunakan untuk istirahat selama waktu pengamatan dilakukan. Hal ini sesuai dengan yang dinyatakan oleh Nurjaeni (2001), bahwa, Kuskus Beruang menggunakan waktunya sebanyak $63,4 \%$ untuk istirahat dan tidur, $23 \%$ untuk merawat tubuh, $7,5 \%$ untuk berpindah tempat, $5,6 \%$ untuk makan dan $0,4 \%$ untuk aktifitas social.

\section{Aktifitas Mencari Makan Kuskus Beruang}

Perilaku Kuskus Beruang mencari makan setelah Kuskus Beruang istirahat dalam waktu yang cukup lama. Tabel 2 menunjukkan bahwa Kuskus Beruang selama beraktiftas, menggunakan waktu rata-rata 3060 menit untuk mencari makan. Wasktu mencari makan dilakukan pada pagi, sing dan sore hari. Sesuai dengan pernyataan sebelumnya bahwa, Kuskus Beruang hanya menggunakan 5-6\% waktunya dalam sehari untuk mencari makan.

\section{Tabel 2. Waktu aktifitas Kuskus Beruang selama mencari makan}

\begin{tabular}{lll}
\hline Waktu & Lama aktifitas & \\
\cline { 2 - 3 } Pengamatan & Jam & Menit \\
\hline Pagi & $07: 00-08: 15$ & 75 \\
Siang & $11: 30-12: 00$ & 30 \\
Sore & $15: 00-15: 55$ & 55 \\
\hline
\end{tabular}

Sumber: Data primer setelah diolah, 2019

\section{Aktifitas Kuskus Beruang sedang berjalan (berpindah tempat)}

Tabel 3. Waktu aktifitas Kuskus Beruang selama berjalan

\begin{tabular}{llc}
\hline Waktu & Lama aktifitas & Menit \\
\cline { 2 - 3 } Pengamatan & Jam & 25 \\
Pagi & $08: 15-08: 40$ & 20 \\
Siang & $12: 00-12: 20$ & 15 \\
Sore & $15: 55-16: 10$ &
\end{tabular}

Sumber: Data primer setelah diolah, 2019

Perilaku berjalan ini dilakukan pada saat Kuskus Beruang mencari tempat untuk tidur, mencari makan ataupun setelah makan. Hasil pengamatan menunjukkan bahwa, Kuskus Beruang lebih aktif berjalan pada pagi hari dibanding siang atau sore hari, karena pada pagi hari Kuskus Beruang berjalan untuk mencari makan. Tabel 3 menunjukkan bahwa waktu yang digunakan Kuskus Beruang untuk berpindah tempat hampir sama lamanya dengan waktu yang digunakan Kuskus Beruang mencari makan setiap harinya. Hal ini disebabkan, waktu yang digunakan Kuskus Beruang berpindah 
Volume 2 Nomor 1 Juli 2020:20-26

tempat atau berjalan adalah untuk mencari makan. Berdasarkan hasil pengamatan yang dilakukan, selain digunakan mencari makan Kuskus Beruang juga berpindah tempat atau berjalan untuk melakukan aktifitas sosialnya.

\section{Aktifititas Kuskus Beruang sedang diam}

Kuskus Beruang biasanya memilih untuk diam dan duduk di tempat ketika mulai merasa terganggu. Saat Kuskus Beruang menyadari kehadiran manusia disekitarnya, satwa ini akan menunjukkan posisi membeku (freeze). Hal ini merupakan salah satu bentuk perlindungan diri yang dilakukan oleh Kuskus Beruang jika merasa terancam terhadap keberadaan manusia atau hewan lain disekitarnya. Selama kegiatan diam dilakukan, Kuskus Beruang hanya kan duduk terdiam dan tidak menunjukkan perubahan posisi dan aktifitas dalam waktu yang lama. Mata Kuskus Beruang akan tetap terbuka dan sambil terdiam akan mengawasi lingkungan disekitarnya. (Nugraha, 2017).

\section{Tabel 4.Waktu Aktifitas Kuskus Beruang terdiam}

\begin{tabular}{lll}
\hline Waktu & Lama aktifitas & \\
\cline { 2 - 3 } Pengamatan & Jam & Menit \\
\hline Pagi & $08: 40-09: 25$ & 45 \\
Siang & - & - \\
Sore & $16: 10-17: 00$ & 50 \\
\hline
\end{tabular}

Sumber: Data primer setelah diolah, 2019

Tabel 4 menunjukkan lamanya aktifitas diam yang dilakukan Kuskus Beruang ketika pengamatan berlangsung. Pada saat melakukan pengamatan pagi dan sore hari tidak mendapatkan tempat yang cukup strategis untuk melakukan pengamatan sehingga menyebabkan Kuskus Beruang menyadari keberadaan manusia disekitarnya. Hal inilah yang menyebabkan Kuskus Beruang tidak melakukan aktifitas apapun selama pengamatan berlangsung mulai dari pukul 08:40 - 09:25 pagi atau selama 45 menit Kuskus Beruang hanya diam dan duduk saja. Pada saat berdiam diri, Kuskus Beruang hanya akan duduk dengan posisi ekor yang dililitkan pada batang atau dahan pohon tempat Kusksus Beruang berdiam diri dengan mata tetap terbuka.

\section{Aktifitas Kuskus Beruang Merawat}

\section{Tubuh (Grooming)}

Dari hasil pengamatan terlihat Kuskus Beruang melakukan aktifitas ini dengan cara menggosokkan badannya pada bagian batang pohon papaya. Saat melakukan aktifitas grooming Kuskus Beruang menempelkan seluruh bagian depan tubuhnya sambil digosokkan pada batang pohon papaya. Tabel 5 menunjukan aktifitas Kuskus Beruang merawat tubuhnya hanya pada pagi hari pada pukul 09:25 - 10:00. Selama 35 menit berlangsung, Kuskus Beruang juga mencari posisi yang nyaman pada saat melakukan aktifitas ini.

Hasil penelitian menujunkan persentase aktivitas Kuskus Beruang dalam satu hari pengamatan mulai dari istirahat, makan, berpindah tempat, diam dan merawat tubuh, adalah sebagai berikut.

Tabel 5. Aktifitas Kuskus Beruang Merawat Tubuh

\begin{tabular}{lll}
\hline Waktu & Lama aktifitas & \\
\cline { 2 - 3 } Pengamatan & Jam & Menit \\
\hline Pagi & $09: 25-10: 00$ & 35 \\
Siang & - & - \\
Sore & - & - \\
\hline
\end{tabular}

Sumber: Data primer setelah diolah, 2019 
Tabel 6. Persentase perilaku Kuskus Beruang (Aliurops Ursinus)

\begin{tabular}{|c|c|c|c|}
\hline No & $\begin{array}{l}\text { Aktivitas Kuskus } \\
\text { beruang }\end{array}$ & $\begin{array}{l}\text { Waktu yang } \\
\text { dibutuhkan } \\
\text { ( Menit) }\end{array}$ & $\begin{array}{l}\text { Persentase } \\
(\%)\end{array}$ \\
\hline 1 & Istirahat & 370 & 52 \\
\hline 2 & Makan & 160 & 22 \\
\hline 3 & Berpindah tempat & 60 & 8 \\
\hline 4 & Diam & 95 & 13 \\
\hline \multirow[t]{2}{*}{5} & Merawat tubuh & 35 & 5 \\
\hline & Jumlah & 720 & $100 \%$ \\
\hline
\end{tabular}

Sumber: Data primer setelah diolah, 2019

Tabel 6 menunjukkan tingkah laku Kuskus Beruang di Cagar Alam Tangale, dalam satu hari pengamatan aktivitas adalah sebagai berikut: 370 menit atau 52\% adalah aktivitas istirahat, aktivitas makan memakan waktu sebesar 160 menit atau $22 \%$, aktivitas berpindah tempat sebesar 60 menit atau $8 \%$, aktivitas diam sebesar 90 menit atau $13 \%$ dan aktivitas grooming sebesar 35 menit atau 5\%. Hal ini kurang lebih sama dengan hasil penelitian Talumepa, et al (2016) yang menyatakan bahwa aktivitas Kuskus Beruang untuk beristirahat sebesar 56.86\%, aktivitas makan sebesar 26,99\%, aktivitas berpindah tempat sebesar $15.11 \%$ dan aktivitas grooming atau merawat tubuh

\section{Jenis Pakan Kuskus Beruang}

Tabel 7. Jenis pakan Kuskus Beruang di Cagar Alam Tangale

\begin{tabular}{|c|c|c|c|c|c|}
\hline No & Nama lokal & Nama ilmiah & Famili & $\begin{array}{l}\text { Bagian } \\
\text { yang dimakan }\end{array}$ & Habitus \\
\hline 1 & Randu & $\begin{array}{l}\text { Ceiba } \\
\text { patandra } \\
\text { gaertn }\end{array}$ & Malvaceae & $\begin{array}{l}\text { Batang dan } \\
\text { daun muda } \\
\text { bagian pucuk }\end{array}$ & Pohon \\
\hline 2 & Pepaya & $\begin{array}{l}\text { Carica } \\
\text { papaya } \mathrm{L} .\end{array}$ & Caricaceae & $\begin{array}{l}\text { Daun muda } \\
\text { bagian pucuk }\end{array}$ & Pohon \\
\hline
\end{tabular}

Sumber: Data primer setelah diolah, 2019

Pada Tabel 7 menjelaskan terdapat dua jenis pakan yang konsumsi oleh Kuskus Beruang yaitu batang dan daun mudah bagian pucuk pada pohon kapuk, kemudian pada pohon pepaya Kuskus Beruang memilih jenis pakan daun mudah pada bagian pucuk. Hal ini sesuai dengan pernyataan Talumepa et al. (2016), bahwa saat memilih makanan Kuskus Beruang cenderung memilih bagian pucuk dan daun muda saja pada jenis tanaman yang menjadi sebesar $1 \%$. Perbedaan yang terdapat pada hasil penelitian ini dengan hasil penilitian Talumepa, et.al (2016) adalah pada penelitian Talumepa tidak mencantumkan besar persentase untuk aktivitas diam yang dilakukan Kuskus Beruang di Cagar Alam Tangkoko Batu Angus karena menurut pengamatannya aktivitas ini hanya dilakukan dalam dua menit saja. Hasil ini berbeda sangat jauh dengan hasil pengamatan Achmad, et al (2014) yang menyebutkan bahwa pada pengamatannya, aktivitas istirahat Kuskus Beruang sebesar $82.17 \%$, aktivitas makan sebesar $11.7 \%$, dan aktivitas berpindah tempat sebesar $4.38 \%$. 
Volume 2 Nomor 1 Juli 2020:20-26

dan N 00'43.509” - E 122'43.583”. Status Kuskus Beruang di Kawsan Cagar Alam Tangale adalah satwa endemik yang dilindungi. Untuk menemukan satwa ini cukup sulit dan membutuhkan waktu yang cukup lama pula, karena lokasi Cagar Alam Tangale yang jauh dari lokasi pemukiman. Jika beruntung, Kuskus Beruang akan mudah ditemukan pada kebun-kebun masyarakat yang berbatasan langsung dengan Kawasan Cagar Alam Tangale untuk mencari makan. Data BKSDA Sulut menyebutkan bahwa sampai dengan saat ini pelestarian Kuskus Beruang masih terus dilakukan, karena populasinya yang kian menurun akibat terjadinya kebakaran hutan dalam kawasan Cagara Alam Tangale. Jumlah Kuskus Beruang saat ini berjumlah 20 ekor yang terdiri dari 7 ekor Kuskus Beruang jantan dan 13 ekor Kuskus Beruang betina. (Dephut, 2015)

\section{KESIMPULAN}

Kuskus beruang ((Ailurops Ursinus) memiliki beberapa jenis aktiftas yang dilakuakn dalam satu hari waktu pengamatan. Sebagian besar waktu digunakan Kuskus Beruang untuk beristirahat yaitu sebesar $52 \%$, waktu yang digunakan untuk mencari makan sebesar $22 \%$, waktu yang digunakan untuk berpindah tempat sebesar $8 \%$, waktu untuk berdiam diri sebesar $11 \%$ dan waktu untuk merawat tubuh (grooming) sebesar 5\%. Jenis pakan yang menjadi sumber makanan Kuskus Beruang adalah bagian batang daun pucuk daun yang masih muda pada pohon. Perilaku unik dari Kuskus Beruang adalah perilaku diam (freeze) yang dapat dilakukan dalam waktu yang lama. Perilaku diam ditandai dengan Kuskus Beruang yang hanya duduk terdiam sambil melilitkan ekornya pada batang atau ranting pohon tempat Kuskus berdiam diri.

\section{DAFTAR PUSTAKA}

Achmad. A., Ngakan P.O., Maulany. R., Asrianny. (2016). Potensi Pakan dan Preferensi bersarang Kuskus
Beruang (Ailurops Ursinus) di Hutan

Pendidikan Unhas. Prosiding Seminar Nasional Biologi 2016. Makassar.

Departemen Kehutanan. 2008. Rencana Pengelolaan Jangka Panjang Cagar Alam Tangale. Balai Konservasi Sumber Daya Alam Sulawesi Utara. Mana.

Depertemen Kehutanan. 2015, Penetapan Kawasan Konservasi Cagar Alam Tangale. Balai Konservasi Sumber Daya Alam.

Darenoh. C., Qoeljoe. E.,, Butarbutar R.B. (2019) Aktifitas Diurnal Kuskus Beruang Betina (Ailurops Ursinus) di Pusat Penyalamatan Satwa Tasikoki Minahasa Utara. Jurnal Bios Logos 9(1), 08-14.

Hasrul.N. dan Ismail Bakrie,. (2016). Penilaian Efektivitas Pengelolaan Kawasan Konservasi di Kawasan Cagar Alam Padang Luway Kabupaten Kutai Barat.

International Union Conservation of Nature, 2008. The IUCN Redlist of Threatened Species. http//www.IUCNredlist.org.html.

[Diakses 10 Juni 2019].

Kinnaird, M.F. 1997. Sulawesi Utara : Sebuah Panduan Sejarah Alam. Alih Bahasa : Nicky Sutadi. GEFBiodiversity Collections Project, Pustlitbang Biologi-LIPI Bogor.

Lis Nurrani. (2013). Pemanfaatan Tradisional Tumbuhan Alam Berkhasiat Obat Oleh Masyarakat Di Sekitar Cagar Alam Tangale. Info BPK Manado Volume 3 No 1.

Mustari, A. H dan Nugraha. R. (2017). Composition and Structure of Vegeatation in Tanjung Peropa Widlife Resereve South-east Sulawesi. Jurnal Wasian, 4(2). Lembaga Penelitian dan Pengembangan Lingkungan dan Kehutanan Manado.

Nugraha. R (2017). Karakteristik Habitat Dan Jenis Pakan Kuskus Beruang (Ailurops Ursinus) Di Suaka 
Margasatwa Tanjung Peropa, Sulawesi Tenggara.

Nurjaeni, 2001. Konsumsi dan Gambaran Umum Kecernaan Pakan Pada Kuskus Beruang (Ailurops Ursinus). Skripsi. Institut Pertanian Bogor. Bogor

Pattiselanno, F. (2007). Perburuan Kuskus (Phalangeridae) oleh Masyarakat Napan di Pulau Ratewi, Nabire, Papua. Jurnal Biodiversitas, 8(4), 274 - 278.

Salas, L. Dickman, C. Helgen, K., Flannery, T. (2008). Ailurops ursinus, Bear Cuscus: The IUCN Redlist of Threatened

Species.http://www.iucnredlist.ord/de tails/40637/0. [Diakses 06 Juni 2019].

Saragih. E.V.I., Sadsoetoeitoeboen. M.J., Pattisellano. F. (2010). The Diet of
Kuskus (Spilocucscus maculatus) in Natural and Captivity Habitat. Jurnal Boscience 2(2), 78-83.

Talumepa, R.S.H, Pratiwi A.A., H. Wungow, Z., Poli, S., Rimbing, C., (2016). Tingkah laku harian Kuskus Beruang (Ailurops ursinus) di Cagar Alam Tangkoko Batu Angus. Jurnal Zootek, 36(1), 174 - 183.

Wartika R.F, Nurjaeni R. Mutia,. D. Diapari. (2004). Kemampuan Cerna Kuskus Beruang (Ailurops ursinus) terhadap Pakan Alternatif di Penangkaran. Jurusan Biologi.

Wowor. M.F., H.J. Kiroh., V. Rawung., H. Rawung. (2016). Estimasi Kepadatan Kuskus Beruang (Ailurops ursinus) di Cagar Alam Tangkoko Batu Angus Kota Bitung. Jurnal Zootek, 36(2), 395 - 404. 